\title{
Production of embryo-callus-regenerated hybrids between Triticum aestivum and Agropyron cristatum possessing one $B$ chromosome
}

\author{
Q Chen 1, J Jahier 1*, Y Cauderon 2 \\ ${ }_{1}$ INRA, Station d'Amélioration des Plantes, BP 29, 35650 Le Rheu; \\ 2 INRA, Station d'Amélioration des Plantes, 78026 Versailles Cedex, France
}

(Received 13 February 1992; accepted 18 May 1992)

\begin{abstract}
Summary - Plant regeneration from immature intergeneric embryos through direct callus induction was investigated in the case of hybridization between $T$ aestivum $\mathrm{cv}$ Chinese Spring $(2 n=6 x=42, \mathrm{AABBDD})$ and $A$ cristatum $4 x$ with one B chromosome $(2 n=4 x=28+1 \mathrm{~B}$, PPPP). Twenty-three abnormal immature hybrid embryos were directly cultured on MS solid medium with $2 \mathrm{mg} / L$ 2,4-D to induce calli which were then transferred to hormone free MS medium for plant regeneration. All the embryos formed calli. Plantlets were regenerated from $56 \%$ of the calli induced from the torpedo-shaped abnormal embryos without scutellum and $82 \%$ of calli from small abnormal embryos with scutellum. Forty-three regenerated plantlets were produced from a single hybrid embryo. Most hybrid plants had $2 n=5 x=35$ chromosomes, and some had 1-4 B chromosomes, indicating that Agropyron B chromosomes can be maintained through in vitro culture in wheat $x$ Agropyron hybrids. Since the small abnormal hybrid embryos are produced at a high frequency following intergeneric hybridizations, the utilization of the embryo culture technique described should be effective in rescuing them.
\end{abstract}

wheat x Agropyron hybrid / abnormal hybrid embryo / callus culture / plant regeneration / B chromosome

Résumé - Production de plantes régénérées à partir de cals issus d'embryons hybrides entre Triticum aestivum et Agropyron cristatum possédant un chromosome B. La régénération de plantes à partir d'embryons intergénériques immatures en utilisant la technique d'induction directe de cals a été étudiée dans le cas d'une hybridation entre T aestivum $c v$ Chinese Spring $(2 n=6 x=42, A A B B D D)$ et $A$ cristatum $4 x$ possédant un chromosome $B(2 n=4 x$ $=28+1 B, P P P P)$. Vingt-trois embryons hybrides anormaux ont été cultivés sur un milieu solide MS contenant $2 \mathrm{mg} / 1$ de 2,4-D pour induire des cals. Ces derniers ont été repiqués sur un milieu MS sans hormone permettant la régénération de plantes. Tous les embryons ont formé un cal. Cinquante six pourcent des cals induits à partir d'embryons au stade torpille et sans scutellum et $82 \%$ des cals d'embryons petits et avec scutellum ont donné des plantes. Un seul embryon a permis l'obtention de 43 de ces plantes. La plupart des plantes hybrides étaient à $2 \mathrm{n}=5 \mathrm{x}=35$ chromosomes, les autres possédaient en outre de 1 à 4 chromosomes $B$. Ceci démontre que les chromosomes $B$ des hybrides blé $x$ Agropyron peuvent être maintenus en culture in vitro. Étant donné que les hybridations interspécifiques produisent un fort pourcentage de petits embryos anormaux, l'utilisation de la technique décrite devrait être efficace pour assurer la production de plantes hybrides.

hybride blé x Agropyron / embryon hybride / culture de cal / régénération de plante / chromosome B

* Correspondence and reprints 


\section{INTRODUCTION}

Agropyron Gaertn is a genus containing allogamous and perennial species in the tribe Triticeae. As desirable forages and potential donors of interesting characteristics to wheat, Agropyron species are receiving increasing attention from breeders, agronomists and cytogeneticists (Dewey, 1984; Sharma et al, 1984; Mujeeb-Kazi et al, 1989). Hybridization of Triticum aestivum with different diploid and tetraploid species of Agropyron has been investigated (White, 1940; Smith, 1943; Mujeeb-Kazi et al, 1989; Chen et al, 1989a, 1990; Limin and Fowler, 1990; Ahmad and Comeau, 1991; Li and Dong, 1991) and found to be very difficult with a low frequency of crossability (from $0-3 \%$ of poilinated florets). Moreover, the frequency of normal hybrid embryos was usually lower than $40 \%$, and they usually aborted within 12-15 days after pollination. Some of these embryos could be rescued when transplanted to a defined artificial medium while other abnormal hybrid embryos failed to develop viable seedlings by conventional embryo rescue techniques (Chen et al, 1989a, 1990; Limin and Fowler, 1990; Li and Dong, 1991). This phenomenon is generally observed in most intergeneric hybridizations within the tribe Triticeae (Taira and Larter, 1978; Sharma and Gill, 1983; Park and Walton, 1989; Chen, 1991). Obviously the development of a simple and effective method to rescue these embryos would be most valuable. Moreover, as the fertility of the intergeneric hybrids is low, the number of $F_{1}$ plants may limit the production of the required number of progenies for studies and selection. Recently, the technique of callus induction and plant regeneration from immature hybrid embryos has been regarded as an alternative way to develop hybrid plants (Park and Walton, 1989; Shao and Taira, 1990).

This paper reports a study of possibility of callus induction and plant regeneration from abnormal immature hybrid embryos in the case of hybridization between wheat and Agropyron cristatum. As this latter possessed a $B$ chromosome, the possible influence of in vitro culture on maintaining $\mathrm{B}$ chromosomes was investigated.

\section{MATERIALS AND METHODS}

$F_{1}$ hybrids were produced during the summer of 1989 from the cross between emasculated plants of Triticum aestivum cv Chinese Spring (CS) $(2 n=6 x=42$, AABBDD) and a tetraploid plant of Agropyron cristatum with one $B$ chromosome (accession 19, $2 n=4 x=$
$28+1 \mathrm{~B}, \mathrm{PPPP})$, collected in Inner Mongolia, China (Chen et al, 1989b).

The pollinated florets of CS were sprayed with GA3 (gibberellic acid, $100 \mathrm{mg} / \mathrm{l}$ ) 24 and $48 \mathrm{~h}$ after pollination. Ten to 12 days after pollination, the immature seeds were harvested, surface sterilized in $5 \%$ sodium hypochlorite solution for $8 \mathrm{~min}$ and rinsed 3 times with sterilized water.

The excised embryos were visually classifed as: 1), normal large embryos with scutellum; 2), abnormal small embryos with scutellum; and 3), abnormal torpedo-shaped embryos without scutellum. The normal embryos were placed on solid MS embryo culture medium without 2,4-D (2,4-dichlorophenoxyacetic acid) (Murashige and Skoog, 1962). All the abnormal embryos were directly cultured on the surface of MS solid medium with $2 \mathrm{mg} / \mathrm{l}$ 2,4-D to induce callus formation.

Calli were initiated in a growth chamber at $22-24^{\circ} \mathrm{C}$ with a photoperiod of $8 \mathrm{~h}$ darkness: $16 \mathrm{~h}$ light provided by $20-\mathrm{W}$ fluorescent lamps for 1 month and then subcultured monthly on hormone-free MS medium for plant regeneration. Calli producing shoots were split into individual tillers, which were transferred to $15 \times 180 \mathrm{~mm}$ test tubes containing $10 \mathrm{ml}$ MS medium with $1 \mathrm{mg} / \mathrm{l}$ naphthyl acetic acid (NAA) for promoting root development. After shoots and roots developed, regenerated plants were washed in tap water to remove agar from roots, transferred into small pots and placed in a plastic box in the greenhouse. After 15 days' growth, plantlets were moved to a cold chamber and vernalized for 6 weeks at $4{ }^{\circ} \mathrm{C}$. The plantlets were subsequently transferred and grown in the greenhouse to maturity.

For chromosome count, root tips of seedlings were pretreated in ice water with $\alpha$-bromonaphthalene at $2{ }^{\circ} \mathrm{C}$ for $24 \mathrm{~h}$, fixed in acetic-alcohol (1:3), stained by the Feulgen technique. Slides were prepared using the $1 \%$ acetocarmine squash method.

\section{RESULTS}

The pollination of 504 florets of CS with A cristatum yielded 33 hybrid seeds from which 29 hybrid embryos were recovered. Six large ones with scutellum were cultured on embryo culture medium, 11 remaining small embryos with scutellum and 12 small torpedo-shaped embryos without scutellum were cultured directly on MS callus inducing medium. The results concerning the embryo culture are given in table I. The data on hybrids obtained by the authors in 1988 through the conventional embryo rescue technique are also presented for comparison (Chen et al, 1989a).

Four out of 6 normal embryos germinated after 1-2 weeks' culture and then developed seedlings. The remaining 2 embryos produced calli after 1 month on embryo culture medium. They 
Table I. Number, types of hybrid embryos and results of embryo culture of $F_{1}$ hybrids between Chinese Spring and $A$ cristatum $4 x$.

\begin{tabular}{|c|c|c|c|c|c|c|}
\hline \multirow[t]{2}{*}{ Type of embryos } & \multirow[t]{2}{*}{ Year } & \multirow{2}{*}{$\begin{array}{c}\text { No of embryos } \\
\text { cultured }\end{array}$} & \multirow{2}{*}{$\begin{array}{c}\text { Embryo culture } \\
\begin{array}{c}\text { No of plantlets } \\
\text { obtained }\end{array}\end{array}$} & \multicolumn{3}{|c|}{ Embryo-callus-regeneration } \\
\hline & & & & $\begin{array}{l}\text { No of calli } \\
\text { induced }\end{array}$ & $\begin{array}{l}\text { No of calli } \\
\text { regenerated } \\
\text { plantlets }\end{array}$ & $\begin{array}{l}\text { No of plantlets } \\
\text { regenerated }\end{array}$ \\
\hline \multirow[t]{2}{*}{ Large with scutellum } & 1988 & 8 & 7 & & & \\
\hline & 1989 & 6 & 4 & 2 & 1 & 1 \\
\hline \multirow[t]{2}{*}{ Small with scutellum } & 1988 & 9 & 5 & & & \\
\hline & 1989 & 11 & & 11 & 9 & 57 \\
\hline \multirow[t]{2}{*}{ Torpedo shape without scutellum } & 1988 & 5 & 0 & & & \\
\hline & 1989 & 12 & & 12 & 6 & 6 \\
\hline
\end{tabular}

* Calli produced on hormone free medium were cultured on MS +2,4-D for 1 month.

were transferred to MS callus inducing medium for 4 weeks and then cultured on hormone free MS medium for plant regeneration: one hybrid plantlet was regenerated from a callus subcultured for 2 months.

The 23 abnormal small embryos placed directly on MS callus inducing medium for about 4 weeks produced white or compact calli. Some of them started to develop green regions or leaf-like shoots 28-35 days after callus initiation. These green regions were considered as totipotent calli having the ability to regenerate plants. Indeed they rapidly developed shoots and leaves when excised and placed on hormone-free medium. Some shoots that did not establish an adequate root system in the medium were transferred to MS medium with NAA to induce rooting.

Finally, 9 out of 11 calli derived from the 11 small embryos with scutellum regenerated plantlets. One of them gave 43 hybrid regenerated plants via organogenesis; each of 2 other calli produced 4 generated hybrid plants. Six of 12 calli which developed from 12 torpedo-shaped embryos without scutellum also produced 6 hybrid plantlets. The remaining calli formed only roots but no shoots and attempts to regenerate plants from the calli were unsuccessful.

For 12 regenerated plants derived from small abnormal embryos, chromosome counts were made on root tip meristems: 8 of them had 35 chromosomes and the remaining ones possessed in addition $1 \mathrm{~B}$ chromosome (3 plants) or 4 B chromosomes (1 plant) (fig 1).

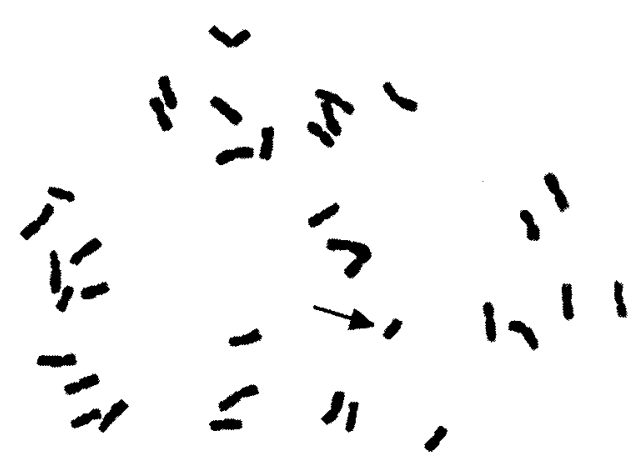

Fig 1. Somatic chromosomes in a regenerated plant from callus induced from abnormal hybrid embryo between $T$ aestivum $\mathrm{cv}$ Chinese Spring $\times$ A cristatum, $2 n=5 x=35+1 \mathrm{~B}(\mathcal{A})$.

\section{DISCUSSION AND CONCLUSION}

Intergeneric hybrids between $T$ aestivum cv Chinese Spring and tetraploid $A$ cristatum had been obtained by the authors in 1988 through the conventional embryo rescue technique (Chen et al, 1989a). This paper is the first report of hybrid plant regeneration from immature embryos of this intergeneric hybrid through direct callus induction. All the small abnormal hybrid embryos produced calli on MS callus inducing medium. In the case of the 11 calli from small embryos with scutellum, plantlets were regenerated from 9 of them $(82 \%)$ but in 1988 , only 5 plants $(56 \%)$ were produced from 9 similar embryos by conventional embryo rescue technique (table I). In the case of torpedo-shaped embryos without 
scutellum, 6 hybrid plants were obtained from the 12 calli whereas no plant was obtained in 1988 from 5 embryos. These results showed that the technique described in this study was effective in obtaining intergeneric hybrids from immature hybrid embryos by callus induction and plant regeneration. This fact is of great value for rescuing small abnormal embryos, as in intergeneric hybridization in the tribe Triticeae.

The evidence from this study indicates that, provided that immature hybrid embryos are from a responsive genotype, callus formation and plant regeneration can be achieved at a very high frequency. Our results differ from those obtained earlier by Park and Walton (1989) on the same medium but with different genotypes. In their study, immature hybrid embryos of Elymus canadensis and Secale cereale were first cultured on hormone-free medium for a period. Those which did not germinate were placed on the callus inducing medium, with the result that only 1 out of the 23 embryos (4.4\%) produced a white and compact callus. Four hybrid plants were regenerated from this callus. This difference in response might be attributed to distinct genotypes having differing regeneration ability and/or to a different culture technique. In our study, excised small abnormal embryos were cultured directly on MS callus inducing medium. Thus, the hybrid embryo cells retained their capacity to form totipotent calli able to regenerate plantlets at a high frequency. Generally the younger the explant is, the more readily organ formation occurs in vitro (Thorpe and Patel, 1984).

Our results also demonstrated that the use of the technique of direct callus induction and plant regeneration from immature hybrid embryos allows not only plant regeneration at a high frequency but also vegetative multiplication during culture. In the conventional embryo rescue technique, one hybrid embryo produces only one hybrid plant. But in the present study, one of the embryo-derived calli yielded as many as 43 hybrid plants. A second advantage of the technique is thus that one can produce vegetative clones in vitro and possibly obtain useful interspecific somaclonal variants. This is particularly interesting in the case of wheat $x$ Agropyron species hybrids. Indeed, since they are highly sterile, ensuring a $B C$ progeny requires many plants of the same genotype.

Additionally, this study showed that Agropyron $B$ chromosomes in wheat $x$ Agropyron hybrids can be maintained through in vitro culture. There are conflicting reports on the behaviour of $B$ chromosomes under in vitro culture conditions. For example, in the case of Cymbopogon martinii, selective elimination of $\mathrm{B}$ chromosomes occurred (Sreenath and Jagadishchandra, 1988) whereas in maize they were conserved (Das and Widholm, 1982). In our case, the production of plants with and without $B$ chromosomes from a single intergeneric embryo allows analysis of incidence of $B$ chromosomes on different features including meiotic pairing in intergeneric hybrids to be made. A more detailed analysis will have to be carried out to see if, as in the case of rye (Asami et al, 1976), the presence of B chromosomes brings about more chromosomal rearrangements, particularly between A chromosomes. If so, this situation could be exploited to transfer Agropyron genetic information into wheat, which is nearly impossible by manipulating the pairing control system of wheat since the level of wheat - Agropyron allosyndetic pairing is very low (Chen et al, 1990).

\section{ACKNOWLEDGMENT}

The authors thank the International Board of Plant Genetic Resources (IBPGR) for supporting this study.

\section{REFERENCES}

Ahmad F, Comeau A (1991) A new intergeneric hybrid between Triticum aestivum $\mathrm{L}$ and Agropyron fragile (Roth) Candargy: variation in $A$ fragile for suppression of the wheat Ph-locus activity. Plant Breeding 106, 275-283

Asami H, Inomata A, Okamoto M (1976) Chromosome variation in callus cells derived from Secale cereale $L$ with and without B chromosome. Jpn J Genet 51, 297-303

Chen Q (1991) Etude cytogénétique des Agropyron Gaertn de Mongolie Intérieure et de leurs hybrides avec le blé. Thèse, Univ Rennes I, France, 159 pp

Chen Q, Jahier J, Cauderon $Y$ (1989a) Production and cytogenetical studies of hybrids between Triticum aestivum $\mathrm{L}$ Thell and Agropyron cristatum (L) Gaertn. CR Acad Sci Paris Ser 3, 308, 425-430

Chen Q, Jahier J, Cauderon Y (1989b) Cytological studies on Agropyron Gaertn species from Inner Mongolia, China. C R Acad Sci Paris, Ser 3, 309, 519-525

Chen Q, Jahier J, Cauderon $Y$ (1990) Intergenetic hybrids between Triticum aestivum and three crested wheat grasses: Agropyron mogolicum, A michnoi and $A$ desertorum. Genome 33, 663-667 
Das PK, Widholm JM (1982) Tissue culture of Zea mays seedlings with $\mathrm{B}$ chromosomes. In: Int Congr Plant Tissue Cell Culture, Int Assoc Plant Tissue Culture Tokyo, $189 \mathrm{pp}$

Dewey DR (1984) The genomic system of classification as a guide to intergeneric hybridization with the perennial Triticeae. In: Gene Manipulation in Plant Improvement. 16th Stadler Gent Symp (Gustafson JP, ed) Plenum Press New York, 209-279

Li L, Dong $Y$ (1991) Hybridization between Triticum aestivum $L$ and Agropyron michnoi Roshev. 1. Production and cytogenetic study of $F_{1}$ hybrids. Theor App/ Genet 81, 312-316

Limin AE, Fowler DB (1990) An interspecific hybrid and amphiploid produced from Triticum aestivum crosses with Agropyron cristatum and Agropyron desertorum. Genome 33, 581-584

Mujeeb-Kazi A, Suh DY, Ter-Kuile N, Farooq S (1989) Production and cytogenetics of Triticum aestivum $\mathrm{L}$ hybrids with some rhizomatous Agropyron species. Theor Appl Genet 77, 162-168

Murashige $T$, Skoog $F$ (1962) A revised medium for rapid growth and bioassay with tobacco tissue cultures. Physiol Plant 15, 473-497

Park CH, Walton PD (1989) Embryo-callusregenerated hybrids and their colchicine-induced amphiploids between Elymus canadensis and Secale cereale. Theor App/ Genet 78, 721-727
Shao ZZ, Taira T (1990) Production of primary Triticale from calluses of immature abnormal hybrid embryos between Triticum durum and Secale cereale. Plant Breeding 105, 81-88

Sharma HC, Gill BS (1983) New hybrids between Agropyron and wheat. 2. Production, morphology and cytogenetic analysis of $F_{1}$ hybrids and backcross derivatives. Theor App/ Genet 66, 111-121

Sharma HC, Gill BS, Uyemoto JK (1984) High levels of resistance in Agropyron species to barley yellow dwart and wheat streak mosaic viruses. Phytopathol Z110, 143-147

Smith DC (1943) Intergeneric hybridization of Triticum and other grasses, principally Agropyron. J Hered 34, 219-224

Sreenath HL, Jagadishchandra KS (1988) In vivo and in vitro instability of $\mathrm{B}$ chromosomes in palmarosa grass (Cymbopogon martinii var motia). Genome 30, 966-973

Taira T, Larter EN (1978) Factors influencing development of wheat-rye hybrid embryos in vitro. Crop Sci $18,348-350$

Thorpe TA, Patel KR (1984) Clonal propagation: adventitious bud. In: Cell Culture and Somatic Cell Genetics of Plants (Vasil IK, ed) Academic Press, New York, 49-60

White WJ (1940) Intergeneric crosses between Triticum and Agropyron. Sci Agric 21, 198-232 